\title{
Analysis of Factors Influencing Cystic Echinococcosis in Northwest Non-Qinghai Tibetan Plateau Regions of China
}

\author{
Xiangman Zeng, ${ }^{1,2,3,4,5}$ Yayi Guan, ${ }^{1,2,3,4 \star}$ Weiping Wu, ${ }^{1,2,3,4 \star}$ Liying Wang, ${ }^{1,2,3,4}$ Huixia Cai, ${ }^{6}$ Qi Fang, ${ }^{1,2,3,4}$ Shicheng Yu, \\ and Canjun Zheng ${ }^{7}$ \\ ${ }^{1}$ National Institute of Parasitic Disease China CDC, Shanghai, China; ${ }^{2}$ Chinese Center for Tropical Diseases Research, Shanghai, China; ${ }^{3}$ National \\ Center for International Research on Tropical Diseases, Ministry of Science and Technology, Shanghai, China; ${ }^{4}$ WHO Collaborating Centre for \\ Tropical Diseases, Shanghai, China; ${ }^{5} \mathrm{HwaMei}$ Hospital, University of Chinese Academy of Sciences, Ningbo, China; ${ }^{6}$ Department of Parasite \\ Control, Qinghai Provincial Institute for Endemic Diseases Prevention and Control, Xining, China; ${ }^{7}$ Chinese Center for Disease Control and \\ Prevention, Beijing, China
}

\begin{abstract}
Cystic echinococcosis (CE) is an important health problem in northwest non-Qinghai Tibetan Plateau regions of China. Understanding CE risk factors may help in formulating effective prevention and control measures. In the current study, negative binomial regression was used to analyze CE-related factors using prevalence data from 147 counties (cities, districts, and banners) in northwest non-Qinghai Tibetan Plateau regions of China gathered from a national survey conducted in 2012, county economic data, and livestock production data for 2012. The negative binomial regression models indicated Echinococcus granulosus infection rate in livestock (odds ratio [OR]: 1.0471, 95\% Cl: $1.0128-1.0825, P=0.0067)$, the mean number of dogs per family (OR: $3.0589,95 \% \mathrm{Cl}: 1.5116-6.1900, P=0.0019)$, the mean number of sheep per family (OR: $1.0431,95 \% \mathrm{Cl}: 1.0027-1.0852, P=0.0365$ ), and the source of drinking water (OR: $0.9808,95 \% \mathrm{Cl}: 0.9627-0.9992, P=0.0413$ ) were correlated with human CE prevalence, whereas altitude, surface temperature, economy, and mean number of cattle per family had a negative association. We found that the positive rate of dog stool coproantigen of Echinococcus was associated with human CE prevalence using the univariate analysis but not after controlling for covariates including the number of dogs per family. This might be partially due to the deworming campaigns that were carried out in most of the researched areas. Therefore, the positive rate of dog stool coproantigen of Echinococcus could not reflect the dog infection rate under natural conditions. These findings indicate that dogs and livestock play the most important role in CE transmission. Further studies should be carried out at the township or village level.
\end{abstract}

\section{INTRODUCTION}

Cystic echinococcosis (CE) is a globally distributed parasitic zoonosis caused by larval stages (metacestodes) of the tapeworm Echinococcus granulosus. ${ }^{1,2}$ Humans become infected through the ingestion of $E$. granulosus eggs, transmitted from infected definitive hosts such as dogs, wolves, other canids, or a contaminated environment. These eggs can then develop into one or several unilocular hydatid cysts causing severe illness and death. ${ }^{2-4}$ Worldwide, human incidence rates can be more than 50 cases per 10,000 people per year in endemic regions. ${ }^{5}$ Annual costs associated with $C E$ treatment and loss in the livestock industry are estimated at three billion U.S. dollars. ${ }^{6}$

Cystic echinococcosis in humans is most commonly found in poor pastoral regions that raise sheep or other livestock (e.g., cattle, goats, and pigs) and keep dogs for guarding or herding purposes. ${ }^{5}$ In a recent meta-analysis, risk factors shown to be associated with $E$. granulosus infections include dogs that are free to roam, feeding dogs with viscera, livestock slaughter at home, slaughterhouses, dog ownership, living in rural areas, low income, age, and gender. ${ }^{7}$ Temperature, humidity, and rainfall affect the prevalence by changing the life span of $E$. granulosus eggs and the living environment of the host. $^{8-11}$ Ten strains of $E$. granulosus have been shown to be pathogenic to humans. G1 (a sheep strain), G6 (a camelid strain), and G7 (a pig strain) strains are responsible for $88.44 \%$, $7.34 \%$, and $3.73 \%$ of human cases of CE worldwide,

\footnotetext{
${ }^{*}$ Address correspondence to Yayi Guan or Weiping Wu, National Institute of Parasitic Diseases, Chinese Center for Disease Control and Prevention, 207 Rui Jin Er Rd., Shanghai 200025, China. E-mails: guan_ml@126.com or wuweiping@hotmail.com
}

respectively. Rare cases caused by G5 (a bovid strain), G8 (a cervid strain), and G10 (a reindeer strain) strains have been identified. No cases of human infection due to G4 (a horse strain) strain have been described. ${ }^{12}$

Cystic echinococcosis is an important public health problem in China. According to the available epidemiological data, human prevalence levels as high as $5-10 \%$ may occur in parts of the Tibet Autonomous Region, Sichuan, Qinghai, Xinjiang Uygur Autonomous Region, Gansu, Ningxia Hui Autonomous Region, and Inner Mongolia Autonomous Region. ${ }^{13-15}$ Two epidemiological types of CE can be distinguished based on topography and geomorphology. ${ }^{16}$ The first area is the Tibetan Plateau, which encompasses most areas of Tibet and Qinghai, Ganzi and Aba prefectures in Sichuan, some parts of Gansu, and Xinjiang Uygur Autonomous Region. The second area is the non-Qinghai Tibetan Plateau, which includes most regions of Gansu, Ningxia Hui Autonomous Region, Inner Mongolia Autonomous Region, Xinjiang Uygur Autonomous Region, and a small subset of Qinghai. The Tibetan Plateau regions receive more attention because of its severe disease burden caused by its unique geographical landscape, vegetation, biological species, climate, culture, lifestyle, and economic conditions. By contrast, the non-Qinghai Tibetan Plateau is often ignored, although the disease is also endemic in this area. A community survey was conducted in Ningxia in 2002 and 2003, and the results showed that CE prevalence, as determined by ultrasonography, was $0-7.4 \%$ (mean $1.6 \%$ ), with the highest prevalence in Baicheng. ${ }^{17} \mathrm{~A}$ sampling survey was conducted in Huining County of Gansu Province from 2011 to 2015; the results for this region demonstrated an annual prevalence of $0.33 \%$ among 70,036 people, as determined by $B$ ultrasound images. The seropositive rate in this region was $4.01 \%$ among 7,952 children, as determined by 
serology examination. ${ }^{18}$ A prevalence screening method based on B ultrasound images was used in Hobukesar Mongolian Autonomous County of the Xinjiang Uygur Autonomous Region in 2007, and the results showed that the rate of human CE was $4.0 \%$ and the infection rate in sheep was $3.8 \% .^{19}$

Several studies have evaluated factors influencing human $\mathrm{CE}$ in the non-Qinghai Tibetan Plateau in recent years. Six hundred twenty-seven volunteers in three villages were surveyed in Hobukesar Mongolian Autonomous County of the Xinjiang Uygur Autonomous Region, and the main risk factors associated with CE included age and slaughtering livestock in households. ${ }^{20}$ The results of a community survey conducted in Guyuan, Longde, and Xiji, Ningxia Hui Autonomous Region, indicated that age and dog ownership are the key risk factors for infection, although drinking well water decreased the risk for CE infections. ${ }^{17}$ A study, based on three cross-sectional surveys during 2002-2013, was conducted to predict spatial variation in the cause of $C E$ and found that $E$. granulosus seropositivity was associated with summer and winter precipitation, landscape fragmentation variables, and the extent of areas covered by forest, shrubland, water, and bareland/ artificial surfaces. ${ }^{21}$ However, these studies occurred in individual cities or counties, and the general representativeness was slightly inadequate.

Thus, in this study, we used data from the national sampling survey carried out in 2012 to analyze the factors influencing CE prevalence in 147 counties (cities and districts) in northwest non-Qinghai Tibetan Plateau regions of China.

\section{MATERIALS AND METHODS}

Study area. The research area, dominated by agriculture and animal husbandry, is located in non-Qinghai Tibetan Plateau regions of western China and contained 55, 17, and 75 counties in Gansu, Ningxia Hui Autonomous Region, and Xinjiang Uygur Autonomous Region, respectively (Figure 1). It covers an area of 2.59 million $\mathrm{km}^{2}$, accounting for $26.86 \%$ of the land area of China, and the most prominent features of the climate are long cold winter, short summer, large diurnal temperature differences, and less precipitation. In 2012, the total population was approximately 43.87 million inhabitants, $43.28 \%$ of whom resided in urban areas and $56.72 \%$ resided in rural areas. ${ }^{22-24}$ These areas were selected because of previous hospital records demonstrating CE transmission or because conditions in the regions were suitable for $\mathrm{CE}$ transmission.

Study data. Data were obtained from a national survey designed by the National Institute of Parasitic Disease, Chinese Center for Disease Control and Prevention, and conducted by staff in provincial and county CDCs in all possible endemic provinces in $2012 .^{25}$ The total number of selected villages in any given county was based on the distribution of the population in pastoral villages, semi-agricultural and

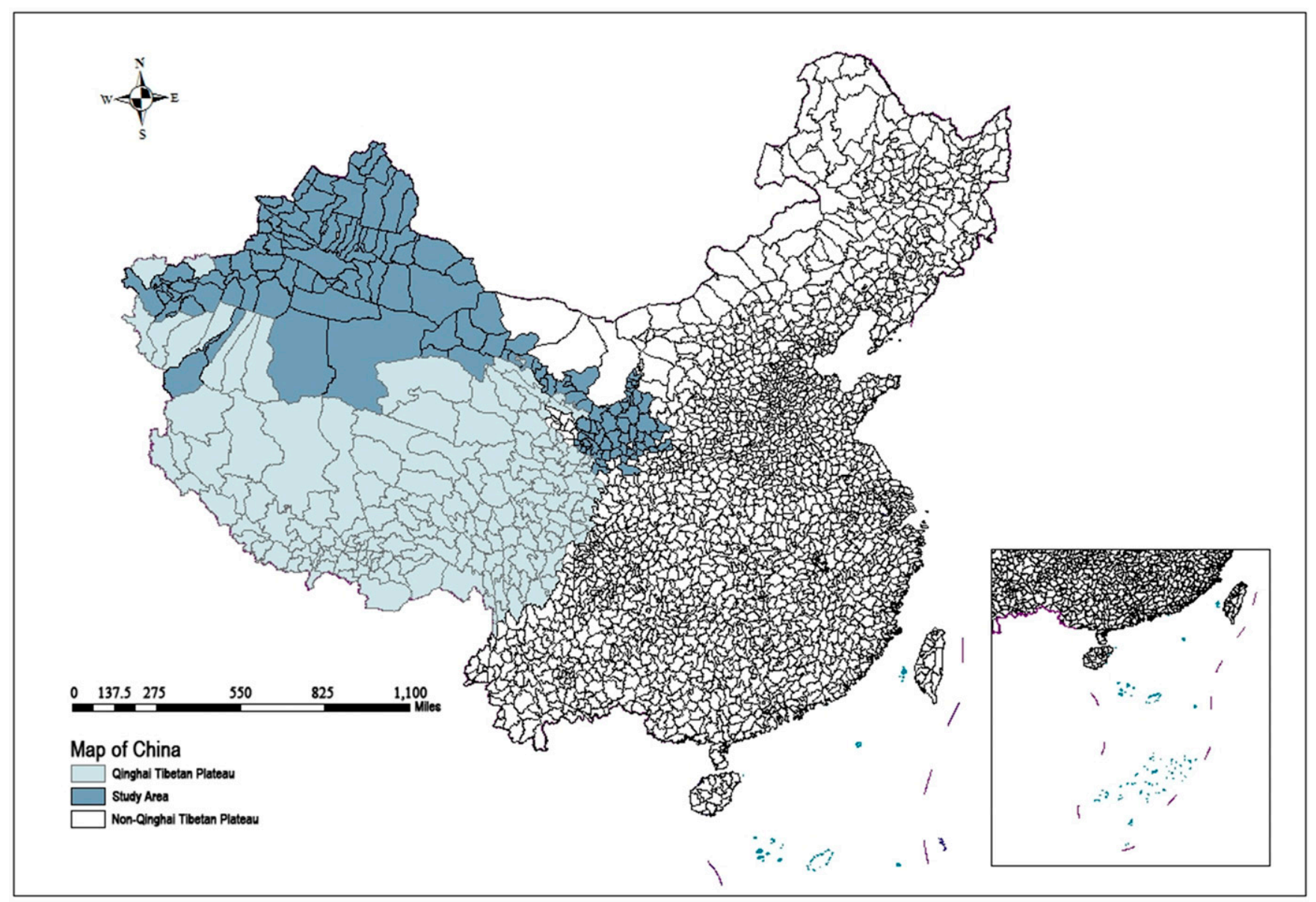

FiguRE 1. Study area of non-Qinghai Tibetan Plateau regions in China. This figure appears in color at www.ajtmh.org. 
semi-pastoral villages, agricultural villages, and towns. A total of 16 villages were randomly selected in a county, and at least 200 residents older than 1 year were checked by B ultrasound accompanied by ELISA (Zhuhai Haitai Bio-Pharmaceutical Co. Ltd., Zhuhai, China) for the suspected cases. Twenty households raising dogs were selected from each surveyed village, and the presence of Echinococcus coproantigen in dog feces was tested using a commercial copro-ELISA kit (Zhuhai Haitai Bio-Pharmaceutical Co. Ltd.). One dog from each house was enrolled in the antigen screening. One thousand locally raised sheep/pigs and 500 cattle (age $>1$ year) were selected for examination for CE infection in internal organs in each studied county. A questionnaire was used to collect the data of the average number of dogs per household and the source of drinking water.

Economic data, including the gross domestic product, local government revenue; local fiscal expenditure; total output values of agriculture, forestry, pasturage, and fishery; gross industrial output; investment in fixed assets; and the livestock production data (including the average number of sheep and cattle per household); were obtained from the 2012 statistical yearbook. ${ }^{22-24}$

Remote sensing data from August 2011 to July 2012, from sources such as the Shuttle Radar Topography Mission 3 (SRTM3) and the Moderate Resolution Imaging Spectroradiometer (MODIS) product satellite (MOD11A2), were downloaded from Geospatial Data Cloud (http://www.gscloud.cn/). A Chinese county boundaries map was obtained from the national basic geographic information system database.

Data processing. The sources of drinking water were divided into three groups: tap and well water, river and spring water, and ditch and pond water. The proportion for the three groups was calculated.

As a difference in altitude of $1 \mathrm{~m}$ had no meaningful effect on the prevalence, we transformed altitude into an ordinal variable with 500-m intervals that started at $298 \mathrm{~m}$ and ended at 4,298 m.

Because a single economic indicator cannot represent the actual economic situation of a region, a comprehensive economic strength index, analyzed by principal components analysis, was proposed. ${ }^{26,27}$ In this study, we also used this method to evaluate the economic level of each research county based on six economic data indices, including the gross domestic product; total output values of agriculture, forestry, pasturage, and fisheries; local government revenue; local fiscal expenditure; investment in fixed assets; and gross industrial output. Thus, we obtained the comprehensive score of economic indicators, which reflected the comprehensive economic strength from the principal component's analysis.

The SRTM3 data were spliced and overlaid with an electronic map in ArcGIS version 10.2 (Esri Inc., Redlands, CA) to calculate the average elevation of the counties. The MOD11A2 products were loaded into MODISTool for projection conversion to calculate the counties' annual average daytime $\left(t_{1}\right)$ and nighttime $\left(t_{2}\right)$ temperature. The annual average land surface temperature (LST) of each county could then be derived using the formula $\mathrm{LST}_{\text {MODIS }}=\left(t_{1}+t_{2}\right) / 2$, which can be converted to LST at Celsius by the formula LST $=$ LST $_{\text {MODIS }} \times 0.02-273.15$.

Statistical analysis. Negative binomial regression based on negative binomial distribution is often used to model events that are not independent (including infectious, genetic, seasonal, endemic, occupational, and aggregated events). ${ }^{28}$ In this study, we used the chi-squared test to infer whether the number of CE cases in each researched county obeys negative binomial distribution based on the previous research findings that human CE prevalence is nonrandom in spatial distribution and exists as "high-high" and "low-low" aggregations. $^{29}$ The results showed that the data fit the negative binomial distribution $\left(x^{2}=5.9926, P=0.4240\right)$, the aggregation index $(k)$ is 0.7944 , the mean number $(\mu)$ is 4.2313 , the variance $(\lambda[1+k \lambda])$ is 26.7681 , and there was an obvious overdispersion (26.7681/4.2313). ${ }^{30,31}$ Therefore, we used negative binomial regression to analyze the factors influencing CE prevalence in northwest non-Tibetan Plateau regions of China. The number of CE cases in each county was set as the dependent variable. The $E$. granulosus infection rate in livestock, positive rate of the presence of Echinococcus coproantigen in dog stool, mean number of dogs per family, mean number of sheep per family, mean number of cattle per family, average altitude, land surface temperature, comprehensive score of economic indicators, proportion drinking tap and well water, proportion drinking river and spring water, and proportion drinking ditch and pond water were the independent variables. In addition, the number of people investigated in each county was included as an offset variable. Spearman correlation analysis was used for preliminary exploration of the relationship between the prevalence of $\mathrm{CE}$ and the variables. Both univariate analysis and multiple collinearity tests were performed. As there were $25.17 \%$ (37/137) of zeros in observed data, the negative logit hurdle model was also constructed in multivariate analysis. The Akaike's information criterion (AIC), finite-sample corrected version of AIC (AICC), Bayesian information criterion (BIC), deviance and Pearson chi-squared tests were used to assess the model's goodness of fit. Smaller AIC, AICC, and BIC indicate a better model. The goodness of fit of the model gets better with the value of deviance and Pearson chi-squared approaches to $1 .^{31}$

The data were analyzed by SAS version 9.4 (SAS Institute Inc., Cary, NC) for Windows. Measurement of non-normal distribution of data was described by the median and quartile range. The level of statistical significance was set at $P<0.05$.

Ethics statement. The study was approved by the Independent Ethics Committee of the National Institute of Parasitic Disease, Chinese Center for Disease Control and Prevention (August 6, 2012). Information on the study purposes and procedures was provided to all participants before enrollment in 2012, and written informed consent was obtained from all participants.

\section{RESULTS}

Descriptive analysis of variables. As shown in Table 1, among the 147 counties, the prevalence of CE in humans was $0-0.95 \%$, with a median of $0.07 \%$. Descriptive statistics for the variables used in the negative binomial regression analysis are shown in Table 1.

Negative binomial regression. Correlation analysis. Human CE prevalence was positively correlated with the $E$. granulosus infection rate in livestock, the rate of positive dog stool samples for Echinococcus antigen $(r=0.1953, P=$ $0.0178)$, the mean number of dogs per family $(r=0.2722$, $P=0.0009)$, the mean number of sheep per family $(r=0.2336$, $P=0.0044)$, the economic composite index $(r=0.2048, P=$ $0.0128)$, and the proportion drinking river and spring water 
TABLE 1

Descriptive analysis of variables

\begin{tabular}{|c|c|c|c|c|}
\hline Variable & Minimum & Maximum & Median & $\overline{\text { Quartile range }}$ \\
\hline Human cystic echinococcosis prevalence (\%) & 0 & 0.95 & 0.07 & 0.21 \\
\hline Echinococcus granulosus infection rate in livestock (\%) & 0 & 31.10 & 1.18 & 4.31 \\
\hline Positive rate of dog stool coproantigen of Echinococcus (\%) & 0 & 16.87 & 1.56 & 4.37 \\
\hline Mean number of dogs per family & 0.02 & 1.31 & 0.54 & 0.44 \\
\hline Mean number of sheep per family & 0.02 & 62.06 & 4.60 & 6.60 \\
\hline Mean number of cattle per family & 0.01 & 4.63 & 0.74 & 0.87 \\
\hline Average altitude $(\mathrm{m})$ & 298.20 & $4,616.71$ & $1,513.52$ & 763.71 \\
\hline Land surface temperature $\left({ }^{\circ} \mathrm{C}\right)$ & -7.09 & 14.28 & 8.63 & 4.63 \\
\hline Comprehensive score of economic indicators & -1.34 & 7.60 & -0.40 & 1.21 \\
\hline Proportion drinking tap and well water (\%) & 21.86 & 100 & 97.69 & 1.35 \\
\hline Proportion drinking river and spring water (\%) & 0 & 60.12 & 0.84 & 7.35 \\
\hline Proportion drinking ditch and pond water (\%) & 0 & 62.40 & 0.13 & 11.69 \\
\hline
\end{tabular}

( $r=0.1679, P=0.0421)$, and negatively correlated with the proportion drinking tap and well water $(r=-0.2192, P=0.0076)$ (Table 2).

Univariate analysis. A series of univariate negative binomial regression models were constructed to test the individual risk factors in human CE prevalence (Table 3 ). The results showed human CE prevalence to be significantly associated with the rate of positive dog stool samples for Echinococcus antigen (odds ratio [OR]: $1.0614,95 \% \mathrm{Cl}: 1.0011-1.1253, P=0.0459$ ), the mean number of dogs per family (OR: $3.5835,95 \% \mathrm{Cl}$ : 1.7245-7.4467, $P=0.0006)$, the proportion drinking tap and well water (OR: 0.9828, 95\% Cl: 0.9671-0.9987, $P=0.0342$ ).

Multivariate analysis. A multiple collinearity test of all the independent variables was performed before establishing the negative binomial regression model. The results showed the condition index $(1,929.87)$ to be greater than 30 , indicating the existence of internal correlation. Large variance proportion was found in two variables (the proportion drinking river and spring water and the proportion drinking ditch and pond water), indicating a strong collinearity between these two variables. Because of the greater variance in the proportion drinking river and spring water (compared with the proportion drinking ditch and pond water), it was excluded from the multivariate analysis.

All the remaining independent variables, including the E. granulosus infection rate in livestock, the rate of positive dog stool samples for Echinococcus antigen, the mean

TABLE 2

Simple correlation coefficient between human cystic echinococcosis (CE) prevalence and the studied variables

\begin{tabular}{lcc}
\hline & \multicolumn{2}{c}{ Human CE prevalence } \\
\cline { 2 - 3 } \multicolumn{1}{c}{ Variable } & $\begin{array}{c}\text { Spearman correlation } \\
\text { coefficient }\end{array}$ & $P$-value \\
\hline Echinococcus granulosus infection rate in & 0.2666 & 0.0011 \\
$\quad$ livestock & & \\
Positive rate of dog stool coproantigen of & 0.1953 & 0.0178 \\
$\quad$ Echinococcus & & \\
Mean number of dogs per family & 0.2722 & 0.0009 \\
Mean number of sheep per family & 0.2336 & 0.0044 \\
Mean number of cattle per family & 0.0308 & 0.7116 \\
Average altitude & 0.0433 & 0.6030 \\
Land surface temperature & -0.0343 & 0.6799 \\
Comprehensive score of economic & 0.2048 & 0.0128 \\
$\quad$ indicators & & \\
Proportion drinking tap and well water & -0.2192 & 0.0076 \\
Proportion drinking river and spring water & 0.1679 & 0.0421 \\
Proportion drinking ditch and pond water & 0.0627 & 0.4503 \\
\hline
\end{tabular}

number of dogs per family, the mean number of sheep per family, the mean number of cattle per family, the altitude, the land surface temperature, the comprehensive score of economic indicators, the proportion drinking tap and well water, and the proportion drinking ditch and pond water, were studied in the negative binomial regression analysis and negative logit hurdle model. The results showed the negative binomial model with a deviance of 1.2324 and Pearson chisquared value of $1.0200(\mathrm{AIC}=736.4, \mathrm{AICC}=738.7$, and $\mathrm{BIC}=$ 772.3) had a better goodness of fit than the negative logit hurdle model $(\mathrm{AIC}=752.3, \mathrm{AICC}=758.3$, and $\mathrm{BIC}=809.1)$. Thus, human $\mathrm{CE}$ prevalence was associated with the E. granulosus infection rate in livestock (OR: $1.0471,95 \% \mathrm{Cl}$ : 1.0128-1.0825, $P=0.0067$ ), the mean number of dogs per family (OR: $3.0589,95 \% \mathrm{Cl}: 1.5116-6.1900, P=0.0019)$, the mean number of sheep per family (OR: $1.0431,95 \% \mathrm{Cl}$ : 1.0027-1.0852, $P=0.0365)$, and the proportion drinking tap and well water (OR: $0.9808,95 \% \mathrm{Cl}: 0.9627-0.9992, P=$ 0.0413) (Table 4).

\section{DISCUSSION}

The present study showed that human CE prevalence was positively related to the $E$. granulosus infection rate in livestock (OR: $1.0471,95 \% \mathrm{Cl}: 1.0128-1.0825)$, the mean number of dogs per family (OR: $3.0589,95 \% \mathrm{Cl}: 1.5116-6.1900)$, the mean number of sheep per family (OR: 1.0431, 95\% Cl: 1.0027-1.0852), and negatively related to the proportion drinking tap and well water (OR: 0.9808, 95\% Cl: $0.9627-0.9992)$. A 1\% increase in the $E$. granulosus infection rate in livestock was associated with a $4.71 \%$ increase in human CE prevalence. One more sheep or dog per family was associated with a $4.31 \%$ and $2.06 \%$ increase in human CE prevalence, respectively. Each $1 \%$ increase in the proportion drinking tap and well water was associated with a $1.92 \%$ decrease in human CE prevalence.

Dogs and livestock are indispensable elements in the endemic process of CE. ${ }^{5,32}$ In the research areas, keeping livestock such as sheep and goats is very common. Domestic dogs are kept in large populations for their important role in the guarding households, tents, and livestock. There are typically two to four dogs per household, and people are often in close contact with their dogs. ${ }^{32}$ Few slaughterhouses were found in the region; people usually slaughter their livestock for family meat consumption at home. Dogs would have a higher probability of accessing the viscera of livestock, as people often feed the viscera to their dogs, especially during 
TABLE 3

Results arising from univariate analysis of factors associated with human cystic echinococcosis prevalence in non-Qinghai Tibetan Plateau regions of China

\begin{tabular}{|c|c|c|c|c|}
\hline Variable & $\beta$ & $x^{2}$ & $P$-value & Odds ratio $(95 \% \mathrm{Cl})$ \\
\hline Echinococcus granulosus infection rate in livestock & 0.0324 & 2.91 & 0.0883 & $1.0329(0.9952-1.0721)$ \\
\hline Positive rate of dog stool coproantigen of Echinococcus & 0.0596 & 3.99 & 0.0459 & $1.0614(1.0011-1.1253)$ \\
\hline Mean number of dogs per family & 1.2763 & 11.70 & 0.0006 & $3.5835(1.7245-7.4467)$ \\
\hline Mean number of sheep per family & 0.0345 & 3.55 & 0.0596 & $1.0351(0.9986-1.0730)$ \\
\hline Mean number of cattle per family & 0.1067 & 0.68 & 0.4106 & $1.1125(0.8630-1.4343)$ \\
\hline Average altitude & -0.0211 & 0.05 & 0.8287 & $0.9791(0.8090-1.1851)$ \\
\hline Land surface temperature & 0.0070 & 0.06 & 0.8129 & $1.0071(0.9501-1.0674)$ \\
\hline Comprehensive score of economic indicators & 0.0568 & 0.54 & 0.4640 & $1.0585(0.9091-1.2324)$ \\
\hline Proportion drinking tap and well water & -0.0174 & 4.48 & 0.0342 & $0.9828(0.9671-0.9987)$ \\
\hline Proportion drinking river and spring water & 0.0202 & 3.34 & 0.0671 & $1.0204(0.9985-1.0428)$ \\
\hline Proportion drinking ditch and pond water & 0.0134 & 1.11 & 0.2916 & $1.0135(0.9886-1.0391)$ \\
\hline
\end{tabular}

slaughtering season. ${ }^{18-20}$ Infected dogs then transmit fecal eggs to air, soil, and water, forming a complete ecological cycle of CE epidemics between dogs, livestock, and humans.

Sheep play an important role in CE transmission. There was a positive association between the average number of sheep per household and human CE prevalence in our results. Sheep are the principal intermediate animal host and have the highest infection rates. ${ }^{33}$ They are slaughtered in greater numbers than other livestock. ${ }^{34}$ In a recent study, the prevalence of CE in slaughtered sheep was found to be a potential indicator to assess and monitor the transmission status during and after control programs. ${ }^{34}$ Higher cattle herd sizes were associated with increased likelihood of echinococcal infection most likely because of the increased cattle slaughter rates, which increased chances of consuming infected tissues. ${ }^{35}$ However, the average number of cattle per household showed no significant association with human CE prevalence in our study. We attribute this to small cattle herd sizes in the study areas, which could make the role of cattle in CE transmission difficult to demonstrate.

The risk of CE infection in humans is directly affected by canine Echinococcus infection. ${ }^{3-5,32}$ However, the positive rate of dog stool coproantigen of Echinococcus was associated with human $\mathrm{CE}$ prevalence in the univariate analysis only. This finding might be a result of the fact that most counties in the researched area had been included in the national hydatidosis control project. This project started in 2005 and was jointly led by different departments, such as the Department of Development and Reform, Department of Finance, Department of Health, Department of Agriculture, Department of Public Security, Department of Forestry, Department of
Science and Technology, Department of Water Conservancy, Department of Civil Affairs, Department of Education, Department of Ethnic Religion, Department of Broadcasting and Television, Department of News and Propaganda, and Women Union, among others. Monthly campaigns were directed to administer drugs to dogs to expel parasites, and as a result, more than $80 \%$ coverage by the end of 2015 in the nonQinghai Tibetan Plateau was achieved with this project. Dog deworming days were determined according to local conditions in each endemic area and implemented with the participation of village doctors and veterinarians. Therefore, the positive rate of dog stool coproantigen of Echinococcus only represented the infection level after this intervention was implemented and could not reflect the dog infection rate under a natural state.

Previous studies have reported significant influences of altitude, land surface temperature, and economy on human CE prevalence. ${ }^{36-38}$ In higher altitudes, there might be more livestock production, which may promote CE transmission, and lower temperature may prolong the survival of Echinococcus eggs. ${ }^{39}$ Household income levels strongly influenced the choice of healthcare provider, and people may not be aware of the importance of physical examination in poor rural areas of western China. ${ }^{40,41}$ Underdeveloped economies can cause a lack of education, lack of knowledge, and poor hygiene habits, which make people vulnerable to echinococcosis. ${ }^{14}$ However, in our study, there were no statistical differences in human CE prevalence for the three variables in either the univariate analysis or the multivariate analysis. This might be due to the minimal differences existing in these variables between surveyed areas, resulting

TABLE 4

Negative binomial regression analysis of factors associated with human cystic echinococcosis prevalence in non-Qinghai Tibetan Plateau regions of China with all variables

\begin{tabular}{lrrrr}
\hline \multicolumn{1}{c}{ Variable } & \multicolumn{1}{c}{$\beta$} & \multicolumn{1}{c}{$\mathrm{x}^{2}$} & \multicolumn{1}{c}{$P$-value } & Odds ratio (95\% Cl) \\
\hline Intercept & -6.4243 & 31.31 & $<0.0001$ & - \\
Echinococcus granulosus infection rate in livestock & 0.0460 & 7.36 & 0.0067 & $1.0471(1.0128-1.0825)$ \\
Positive rate of dog stool coproantigen of Echinococcus & 0.0235 & 0.75 & 0.3851 & $1.0238(0.9709-1.0796)$ \\
Mean number of dogs per family & 1.1181 & 9.67 & 0.0019 & $3.0589(1.5116-6.1900)$ \\
Mean number of sheep per family & 0.0422 & 4.38 & 0.0365 & $1.0431(1.0027-1.0852)$ \\
Mean number of cattle per family & 0.0712 & 0.24 & 0.6221 & $1.0738(0.8089-1.4256)$ \\
Average altitude & -0.0083 & 0.01 & 0.9344 & $0.9918(0.8146-1.2074)$ \\
Land surface temperature & 0.0375 & 1.04 & 0.3077 & $1.0382(0.9660-1.1158)$ \\
Comprehensive score of economic indicators & -0.0573 & 0.47 & 0.4909 & $0.9443(0.8024-1.1114)$ \\
Proportion drinking tap and well river & -0.0194 & 4.17 & 0.0413 & $0.9808(0.9627-0.9992)$ \\
Proportion drinking ditch and pond water & -0.0214 & 2.20 & 0.1380 & $0.9789(0.9516-1.0069)$ \\
\hline
\end{tabular}


in the influences not being truly observed. If more detailed data of the township or village level could be obtained, the relationship might be better elucidated. The present results indicate that further studies of the township or village are needed.

The present study has some limitations. First, because we conducted this study at the county level with averaged data, differences between counties may be too small to accurately identify risk factors of CE transmission; village-level analyses may be needed to investigate more granular risk factors. The second limitation is the copro-ELISA kit (Zhuhai Haitai BioPharmaceutical Co. Ltd., Zhuhai, Guangdong, China) we used could not distinguish between E. granulosus and Echinococcus multilocularis infection. Finally, we failed to collect human exposure data such as behavior habits and sanitary conditions and could not analyze more environment-related variables such as the surface humidity and the vegetation coverage.

\section{CONCLUSION}

This work elucidated the risk factors that may affect human CE prevalence in non-Qinghai Tibetan Plateau regions of China. The results suggest livestock monitoring, slaughter management, dog deworming, and drinking tap or well water should be the major measures for controlling CE, which might effectively reduce the risk of CE infection in humans in these regions. However, further studies should be carried out at the township or village level, which would help improve the prevention and control of CE in humans.

Received August 27, 2018. Accepted for publication November 23, 2019.

Published online January 13, 2020.

Financial support: We received partial financial support from the WHO/TDR Small Grant (WPDCC0801765), National Science and Technology major projects (2009ZX10004-201), and National Natural Science Foundation of China (no. 81703281).

Authors' addresses: Xiangman Zeng, Ningbo No. 2 Hospital, Zhejiang Province, China, E-mail: zengxiangman8806@126.com. Yayi Guan, Weiping Wu, Liying Wang, and Qi Fang, National Institute of Parasitic Disease, Chinese Center for Disease Control and Prevention, Shanghai, China, E-mails: guan_ml@126.com,wu_wpipd@163.com, wangliyingcdc@163.com, and fang_fiona@hotmail.com. Huixia Cai, Department of Parasite Control, Qinghai Provincial Institute for Endemic Diseases Prevention and Control, Xining, China, E-mail: huixia 1107@163.com. Shicheng Yu and Canjun Zheng, Chinese Center for Disease Control and Prevention, China, E-mails: yusc@chinacdc.cn and zhengcj@chinacdc.cn.

\section{REFERENCES}

1. Agudelo Higuita NI, Brunetti E, McCloskey C, 2016. Cystic echinococcosis. J Clin Microbiol 54: 518-523.

2. Pawlowski ZS, Eckert J, Vuitton D, 2001. Echinococcosis in humans: clinical aspects, diagnosis and treatment. Eckert $\mathrm{J}$, Gemmell M, Meslin FX, Pawlowski ZS, eds. WHO/OIE Manual on Echinococcosis in Humans and Animals: A Public Problem of Global Concern. Paris, France: World Organization for Animal Health, S20-S66. 20-66.

3. Youssefi MR, Mirshafiei S, Moshfegh Z, Soleymani N, Rahimi MT, 2016. Cystic echinococcosis is an occupational disease? J Parasit Dis 40: 586-590.

4. Yuan RX et al., 2017. Prevalence of and risk factors for cystic echinococcosis among herding families in five provinces in western China: a cross-sectional study. Oncotarget 8: 9156891576.

5. Craig PS et al., 2007. Prevention and control of cystic echinococcosis. Lancet Infect Dis 7: 385-394.

6. Budke CM, Deplazes P, Torgerson PR, 2006. Global socioeconomic impact of cystic echinococcosis. Emerg Infect Dis 2: 296-303.

7. Possenti A, Manzano-Román R, Sánchez-Ovejero C, Boufana B, La Torre G, Siles-Lucas M, Casulli A, 2016. Potential risk factors associated with human cystic echinococcosis: systematic review and meta-analysis. PLoS Negl Trop Dis 10: e0005114.

8. Veit P, Bilger B, Schad V, Schäfer J, Frank W, Lucius R, 1995. Influence of environmental factors on the infectivity of Echinococcus multilocularis eggs. Parasitology 10: 79-86.

9. Miterpáková M, Hurníková Z, Antolová D, Dubinský P, 2009. Endoparasites of Red Fox (Vulpes vulpes) in the Slovak Republic with the emphasis on zoonotic species Echinococcus multilocularis and Trichinella spp. Helminthologia 46: 73-79.

10. Atkinson JA, Gray DJ, Clements AC, Barnes TS, McManus DP, Yang YR, 2013. Environmental changes impacting Echinococcus transmission: research to support predictive surveillance and control. Glob Chang Biol 19: 677-688.

11. Thevenet PS, Jensen O, Drut R, Cerrone GE, Grenóvero MS, Alvarez HM, Targovnik HM, Basualdo JA, 2005. Viability and infectiousness of eggs of Echinococcus granulosus aged under natural conditions of inferior arid climate. Vet Parasitol 133: 71-77.

12. Alvarez Rojas CA, Romig T, Lightowlers MW, 2014. Echinococcus granulosus sensu lato genotypes infecting humans-review of current knowledge. Int J Parasitol 44: 9-18.

13. Feng X, Qi X, Yang L, Duan X, Fang B, Gongsang Q, Bartholomot B, Vuitton DA, Wen H, Craig PS, 2015. Human cystic and alveolar echinococcosis in the Tibet autonomous region (TAR), China. J Helminthol 89: 671-679.

14. Huang D, Li R, Qiu J, Sun X, Yuan R, Shi Y, Qu Y, Niu Y, 2018. Geographical environment factors and risk mapping of human cystic echinococcosis in western China. Int $J$ Environ Res Public Health 15: E1729.

15. Yu SH, Wang H, Wu XH, Ma X, Liu PY, Liu YF, Zhao YM, Morishima Y, Kawanaka M, 2008. Cystic and alveolar echinococcosis: an epidemiological survey in a Tibetan population in southeast Qinghai, China. Jpn J Infect Dis 61: 242-246.

16. Jiang CP, 2002. Today's regional distribution of echinococcosis in China [article in Chinese]. Chin Med J 115: 1244-1247.

17. Yang YR et al., 2006. Community surveys and risk factor analysis of human alveolar and cystic echinococcosis in Ningxia Hui autonomous region, China. Bull World Health Organ 84: 714-721. Erratum in: Bull World Health Organ 2006;84(10): 840.

18. He X, Song KF, Gong ZP, Ji WB, Dong ZB, Zhang YQ, Li XL, Cheng $Y L, 2016$. Investigation on endemic status of echinococcosis in Huining County of Gansu province [article in Chinese]. Bull Dis Control Prev 31: 39-41.

19. Li HT, Song T, Duan XY, Qi X, Feng XH, Wang YH, Wen H, 2013. Prevalence of human and ovine hepatic hydatid disease diagnosed by ultrasound in Hobukesar Mongolian autonomous county of Xinjiang [article in Chinese]. Chin $\mathrm{J}$ of Epidemiol 34: 1176-1178.

20. Chu XD, Wang GZ, Feng XH, Er XD, He JH, Wen H, 2010. Risk factors on human cystic echinococcosis in Hobukesar Mongolian autonomous county in Xinjiang [article in Chinese]. Chin J of Epidemiol 31: 297-299.

21. Cadavid Restrepo AM, Yang YR, McManus DP, Gray DJ, Barnes TS, Williams GM, Soares Magalhães RJ, Clements ACA, 2018. Environmental risk factors and changing spatial patterns of human seropositivity for Echinococcus spp. in Xiji County, Ningxia Hui autonomous region, China. Parasit Vectors 11:159.

22. Fan HY, Xian LQ, 2012. Development Year Book of Gansu Province in 2012 [in Chinese]. Beijing, China: China Statistics Press, 126-148.

23. Zhang CP, Mei TY, 2012. Statistical Year Book of Ningxia Hui Autonomous Region in 2012 [in Chinese]. Beijing, China: China Statistics Press, 578-603.

24. Jin JX, 2012. Statistical Year Book of Xinjiang Uygur Autonomous Region in 2012 [in Chinese]. Beijing, China: China Statistics Press, 745-756. 
25. Wu WP et al., 2018. A nationwide sampling survey on echinococcosis in China during 2012-2016 [article in Chinese]. Chin $J$ Parasitol Parasit Dis 36: 1-14.

26. Wang SF, Cui XZ, 2002. Application of the principal component analysis in comprehensive evaluation of Tianjin's economics power [article in Chinese]. J Tianjin Polytech Univ 21: 58-61.

27. Jiang L, Luo H, 2003. Principal components analysis of economic ability of cities in our country's eastern and western region [article in Chinese]. Math Econ 20: 48-53.

28. Chen F, 2007. Multivariate Statistical Analysis of Medicine [in Chinese]. Beijing, China: China Statistics Press, 128-130.

29. Zeng XM, Wang LY, Wu WP, Guan YY, Fang Q, 2014. Cluster analysis of cystic echinococcosis in non-Tibetan Plateau regions [article in Chinese]. Chin J of Schisto Control 26: 180-183.

30. Sun ZQ, 2011. Medical Statistics [in Chinese]. Beijing, China: People's Medical Publishing House, 103-108.

31. Hu LP, 2018. The regression analysis of the negative binomial distribution model for the over-dispersion count data [article in Chinese]. Sichuan Ment Health 31: 399-404.

32. Zhang WB, Zhang ZZ, Wu WP, Shi BX, Li J, Zhou XN, Wen H, McManus DP, 2015. Epidemiology and control of echinococcosis in central Asia, with particular reference to the People's Republic of China. Acta Trop 141: 235-243.

33. Meng QL, Wang GL, Qiao J, Zhu XQ, Liu TL, Song XM, Zhang JS, Wang HS, Cai KJ, Chen CF, 2014. Prevalence of hydatid cysts in livestock animals in Xinjiang, China. Korean J Parasitol 52: 331-334.

34. Yang SJ, Wu WP, Tian T, Zhao JS, Chen K, Wang QY, Feng Z, 2015. Prevalence of cystic echinococcosis in slaughtered sheep as an indicator to assess control progress in Emin County, Xinjiang, China. Korean J Parasitol 53: 355-359.
35. Oba $\mathrm{P}$, Ejobi F, Omadang L, Chamai M, Okwi AL, Othieno E, Inangolet FO, Ocaido M, 2016. Prevalence and risk factors of Echinococcus granulosus infection in dogs in Moroto and Bukedea districts in Uganda. Trop Anim Health Prod 48: 249-254.

36. Fromsa A, Jobre $Y, 2011$. Infection prevalence of hydatidosis (Echinococcus granulosus, Batsch, 1786) in domestic animals in Ethiopia: a synthesis report of previous surveys. Ethiop Vet $J$ 15: 11-33.

37. El Berbri I, Ducrotoy MJ, Petavy AF, Fassifihri O, Shaw AP, Bouslikhane M, Boue F, Welburn SC, Dakkak A, 2015. Knowledge, attitudes and practices with regard to the presence, transmission, impact, and control of cystic echinococcosis in Sidi Kacem province, Morocco. Infect Dis Poverty 4: 48.

38. Hu HH, Wu WP, Guan YY, Wang LY, Wang Q, Cai HX, Huang Y, 2014. A village-based multidisciplinary study on factors affecting the intensity of cystic echinococcosis in an endemic region of the Tibetan Plateau, China. Epidemiol Infect 142: 1214-1220.

39. Eckert J, Gemmell MA, Meslin FX, Pawlowski ZS, 2001. WHO/OIE Manual on Echinococcosis in Humans and Animals: a Public Health Problem of Global Concern. Paris, France: World Organization for Animal Health, 101-135.

40. Yang YR, Williams GM, Craig PS, McManus DP, 2010. Impact of increased economic burden due to human echinococcosis in an underdeveloped rural community of the People's Republic of China. PLoS Negl Trop Dis 4: e801.

41. He Y, Yin JX, 2017. Analysis for epidemiological factors of echinococcosis [article in Chinese]. China Trop Med 17: 418-420. 